\title{
Therapeutic effects of functional orthodontic appliances on cervical spine posture: a retrospective cephalometric study
}

\author{
Maren Ohnmeiß', Gero Kinzinger ${ }^{2}$, Julia Wesselbaum ${ }^{3}$ and Heike M Korbmacher-Steiner ${ }^{3^{*}}$
}

\begin{abstract}
Introduction: Interactions between the cervical spine and the stomatognathic system have been discussed in literature. The present study was conducted to investigate whether, and to what extent, orthodontically induced mandibular advancement produces changes in cervical spine posture. Furthermore, possible appliance-specific effects should be distinguished.

Material and methods: The cephalograms of 64 patients with skeletal class II were analysed before and after mandibular advancement. Linear and angular cephalometric parameters were identified to define the position of the atlanto-occipital and atlantoaxial joints. The total example was divided into two subgroups (comprising 32 individuals each) according to the employed appliance: activator versus bite-jump appliance (BJA). Student's t-test and analysis of covariance were used for statistical analysis.

Results: Overall, a significant straightening of the cervical spine was observed during the treatment. This conclusion is based on changes of Chamberlain ( $p=0.0055), C V T(p=0.0003)$, OPT ( $p<0.0001)$, Redlund-Johnell/Petersson $(p<0.0001)$, McGregor-mC2 ( $p=0.0333)$ and AT-FH ( $p=0.0445)$. Improvements in occipitoatlantal dislocation were also observed in the total sample. Appliance-specific changes were found in the activator subgroup for a number of linear parameters (Chamberlain, McGregor, CVT, OPT, Redlund-Johnell/Petersson). In contrast, only two linear parameters (OPT and Powers ratio) revealed statistically significant changes in the BJA subgroup.

Conclusions: During skeletal class II treatment the position of upper cervical spine changes. In the activator subgroup the observed effects were more pronounced than those in the BJA subgroup. Further studies including a control group comprised with non-treated class II patients are needed to assess whether these effects may be caused directly by the appliances irrespective of growth.
\end{abstract}

Keywords: Angle class II/1, Functional orthodontics, Craniovertebral junction, Cervical spine posture

\section{Introduction}

There is agreement in literature that pathological orthopedic findings are highly prevalent among individuals with orthodontic anomalies [1-5]. These observations have been explained by anatomical, phylogenetic and functional interactions between the masticatory system and the upper cervical spine. Numerous authors have devoted attention to the relationship between occlusal anomalies

\footnotetext{
* Correspondence: korbmacher@staff.uni-marburg.de

${ }^{3}$ Department of Orthodontics, University Hospital Giessen and Marburg, Georg-Voigt-Strasse 3, Marburg 35039, Germany

Full list of author information is available at the end of the article
}

and spinal disorders or deformities. Duyzings [6] reported an association between the postural inclination of the cervical spine and the position of the mandible. Prager [7] demonstrated that the prevalence of malpositioned teeth and jaw anomalies were significantly increased in patients with spinal deformities. Functional interactions of a predominantly morphologic and neuromuscular nature have been suspected to influence the entire system of cranial, cervical, dorsal and sacral structures in such a way that any disturbance of one segment would affect the entire system [8].

Angle class II.1 has been shown to be associated with an atlas inferior position, a habitual lack of an upright 
head posture and a lordosis of the cervical spine. In contrast, Angle class III has been demonstrated to involve an atlas superior position and a kyphosis of the cervical spine [9]. Although many studies have revealed orthodontic and orthopedic interactions, only a few interdisciplinary treatment approaches have been recommended so far: Early orthodontic correction of unilateral crossbite should be regarded as mandatory in patients with scoliosis or torticollis in order to minimize the facial asymmetry related to the orthopedic problem and to stabilize head position $[10,11]$.

Animal experiments have shown that changes of the occlusal height and jaw position led to changes of the upper cervical spine and evoked reactions of the motor and autonomic nervous system [12]. Fink et al. [8] also demonstrated that mandibular advancement led to changes within the craniocervical system and within the region of lumbar, pelvic and hip structures.

Angle class II.1 is the most prevalent anomaly. During growth, orthodontic appliances can produce the orthodontically desired skeletal changes. While the skeletal and profile-changing effects of functional orthodontics in class II patients are widely documented in literature $[13,14]$. None of these reports have specifically addressed changes possibly occurring at the craniocervical level. Therefore, cephalograms, which had been obtained in the context of functional orthodontic treatment of skeletal class II patients, were analysed in terms of changes in the craniocervical level. Furthermore, it should be evaluated whether the effects were appliance specific.

\section{Materials and methods Patients}

The study was conducted according to the Helsinki Declaration. The study design was approved by the Ethic committee of the RWTH Aachen university (reference number AZ 171/08). In this retrospective study only patients with distal occlusion ranging from 0.5 to 1 premolar width, a protruded upper incisor inclination and an ANB angle $>4^{\circ}$ were included. Cases involving gnathic deviation of the mandible and/ or transversal discrepancy were excluded. The successful use of either an activator or a BJA for skeletal treatment was required. A total of 64 patients (35 female and 28 male) with a mean age of 11 years and 2 months met these criteria. The mean skeletal treatment duration was 12 months and 7 days. Appliances were selected according to therapeutic requirements, using an activator for the correction of distal occlusion only and a BJA whenever additional indications for single-tooth movement and/or transversal development of the maxilla were needed. The following null hypothesis was proposed: the skeletal correction of class II evokes changes of the articulations of the craniovertebral junction.

\section{Cephalometry}

Two cephalograms of each patient were available: the first was taken at the beginning; the second after skeletal treatment had been successfully completed. A standardized technique of image acquisition had been used throughout, with the teeth in habitual occlusion and the central beam passing through the porus acusticus externus perpendicular to the film plane. All cephalograms were evaluated by Ricketts analysis (Table 1) in order to assess orthodontic effects and growth.

\section{Parameters}

Table 2 summarizes the atlantoaxial linear and angular parameters used for orthopedic analysis. Head posture and position (Figure 1) were analyzed based on angular measurements of various planes (McGregor, atlas, clivus) relative to McRae's plane. Straightening of the cervical spine (Figure 2) was determined based on the inclination of the atlas toward the Frankfort plane, the clivus-dens angle, and the angle formed by the OPT line against the anterior cranial base. Basilar impression (Figure 3) refers

Table 1 Angles and distances indicating skeletal change in the sagittal and vertical planes

\begin{tabular}{|c|c|c|c|c|c|c|}
\hline Parameters & Active group & p-values & BJA group & $p$-values & All patients & p-values \\
\hline SNA $\left(^{\circ}\right)$ & $-0.76 \pm 1.71$ & $0.0155^{*}$ & $-0.81 \pm 2.66$ & 0.1347 & $-0.78 \pm 2.10$ & $0.0045^{*}$ \\
\hline SNB $\left(^{\circ}\right)$ & $0.24 \pm 2.27$ & 0.5489 & $0.09 \pm 231$ & 0.8465 & $0.2 \pm 2.20$ & 0.4733 \\
\hline ANB $\left(^{\circ}\right)$ & $-0.99 \pm 1.30$ & $0.0001^{* *}$ & $-0.93 \pm 1.16$ & $0.0004^{* *}$ & $-0.99 \pm 1.23$ & $<0.0001^{* *}$ \\
\hline BjØrk sum ${ }^{a}\left({ }^{\circ}\right)$ & $0.72 \pm 4.74$ & 0.3904 & $-1.69 \pm 9.46$ & 0.3691 & $-0.26 \pm 7.02$ & 0.7709 \\
\hline Gonion angle ${ }^{\mathrm{b}}\left({ }^{\circ}\right)$ & $-0.12 \pm 2.31$ & 0.7764 & $-0.80 \pm 4.16$ & 0.3344 & $-0.41 \pm 3.15$ & 0.3095 \\
\hline S-Go (mm) & $2.78 \pm 4.01$ & $0.0004^{*}$ & $3.03 \pm 3.49$ & $0.0002^{* *}$ & $3.00 \pm 3.71$ & $<0.0001^{* *}$ \\
\hline $\mathrm{N}-\mathrm{Me}(\mathrm{mm})$ & $4.81 \pm 3.48$ & $<0.0001^{* *}$ & $4.39 \pm 5.04$ & $0.0002^{* *}$ & $4.69 \pm 4.12$ & $<0.0001^{* *}$ \\
\hline SN/ML $\left({ }^{\circ}\right)$ & $0.85 \pm 3.72$ & 0.1991 & $0.38 \pm 3.38$ & 0.5746 & $0.61 \pm 3.44$ & 0.1642 \\
\hline PE/ML $\left({ }^{\circ}\right)$ & $0.78 \pm 2.55$ & 0.0890 & $-0.22 \pm 3.45$ & 0.7446 & $0.30 \pm 2.95$ & 0.4178 \\
\hline
\end{tabular}

Data are given as mean differences $( \pm$ SD) between posttreatment and baseline values.

Asterisks $\left({ }^{*}\right.$ or $\left.* *\right)$ indicate significant $(p<0.05)$ or highly significant $(p<0.001)$ differences.

${ }^{\mathrm{a} N} \mathrm{~N}-\mathrm{S}-\mathrm{Ar}+\mathrm{S}-\mathrm{Ar}-\mathrm{Go}+\mathrm{Ar}-\mathrm{Go}-\mathrm{Me} ;{ }^{\mathrm{b}} \mathrm{Ar}-\mathrm{Go}-\mathrm{Me}$. 
Table 2 Orthopedic parameters, including landmarks and definitions

\begin{tabular}{ll}
\hline Atlas inclination (modified) & Angle from atlas plane to Frankfort horizontal plane. \\
\hline Atlas plane (AT) & Line drawn through the most anterior and most posterior sites of the atlas. \\
Chamberlain's distance & Distance from dens tip to Chamberlain's line. \\
Chamberlain's line (palato-occipital line) & Line drawn from posterior edge of hard palate to posterior edge of foramen magnum. \\
Clivus-dens angle & Angle between dorsal ends of clivus and dens axis. \\
Dorsal clivus boundary & Dorsal end of clivus \\
Dorsal dens boundary & Dorsal end of dens axis \\
McGregor's line (palato-suboccipital line) & Line from posterior edge of hard palate to most inferior point of squama occipitalis. \\
McRae's line (foramen magnum line) & Line between anterior and posterior edges of foramen magnum. \\
OPT line & Line drawn against the anterior cranial base to define the craniocervical angle. \\
Powers ratio & $\begin{array}{l}\text { Ratio between distances (i) opisthion to dens tip and (ii) Ba to projection center of } \\
\text { arcus posterior atlantis. }\end{array}$ \\
Ranawat's line & $\begin{array}{l}\text { Distance between a line connecting the projection centers of the anterior/posterior } \\
\text { arches of the atlas and the center of the shadow of the axis vertebra. }\end{array}$ \\
Redlund-Johnell/Petersson line & $\begin{array}{l}\text { Distance between McGregor's line and center of inferior endplate of second cervical vertebra (mC2) } \\
\text { Solow/Tallgren sum (modified) }\end{array}$ \\
\hline
\end{tabular}

to cranial displacement of the cervical vertebrae, causing the dens to project itself at the level of the foramen magnum; its presence was verified by measuring the angle of McRae's line to the dorsal dens boundary and the distance from Chamberlain's line to the dens. Occipitoatlantal dislocation (Figures 4 and 5) refers to a shifted position of the atlas relative to the cranial base; it was assessed by the Powers ratio and Ranawat's line, also using the approach by Redlund-Johnell and Petersson of measuring the distance from McGregor's plane to the center of the inferior endplate of the second cervical vertebra, and the complementary technique by Solow and Tallgren of calculating the sum of four specific angles relative to the Frankfort plane.

\section{Measurements}

After scanning the cephalograms, the linear and angular measurements were performed using diagnostic software (Fr win; Computer Konkret AG, Falkenstein, Germany). To ensure comparability among the different cephalograms, the enlargement factor of each cephalogram was individually determined and multiplied for all linear measurements.

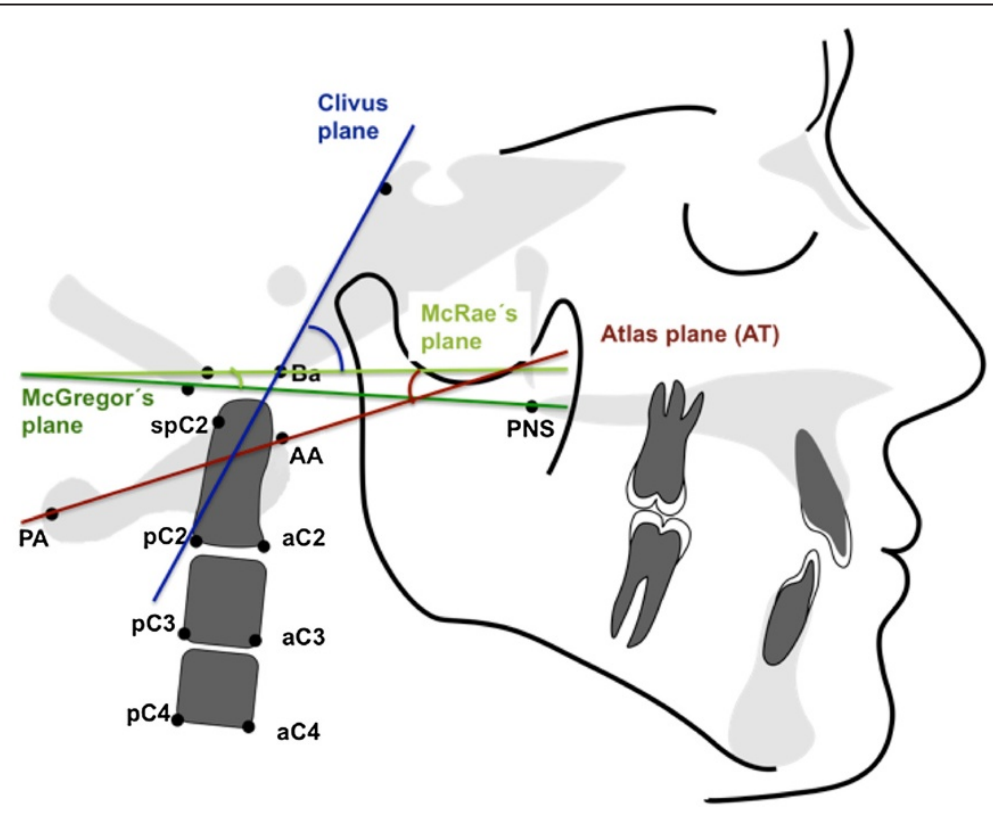

Figure 1 Angular and linear parameters of head posture and position. 


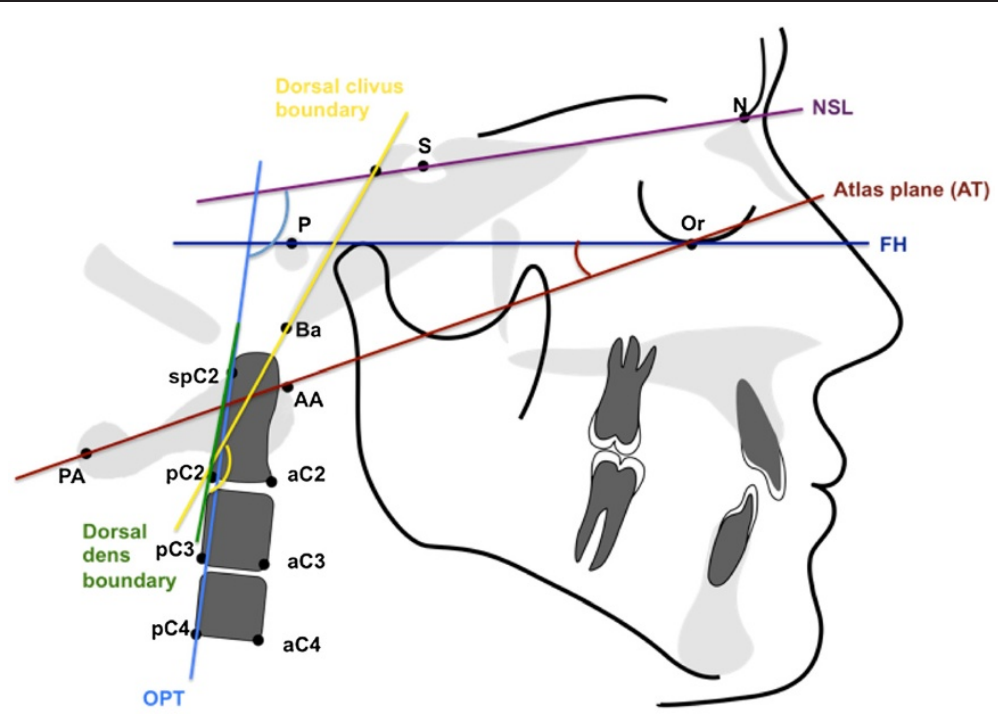

Figure 2 Angular and linear parameters of cervical spine straightening.

Double contours (related to the radiographic technology used) were averaged.

\section{Statistical analysis}

Spreadsheet (Microsoft Excel 2007) and statistics (SAS Version 9.1; SAS Institute Inc., Cary, NC) software was used to analyze data, calculating arithmetic means and standard deviations for all cephalometric parameters. Analysis of covariance was used to evaluate whether any of the findings were linked to the use of the orthodontic appliance. Student's t-test was performed in order to identify any significance between the first and second measurement. The resultant $\mathrm{p}$-values were considered statistically significant at $<0.05$. Normal distribution of the various parameters had been verified beforehand, and the t-test was performed in duplicate - once summarily for all data and once separately for each orthodontic appliance. Analysis of covariance was employed to find out whether the use of a specific orthodontic appliance was linked to any of the values obtained from the posttreatment cephalograms, using the corresponding baseline values as covariable. Multivariate regression yielded no statistically significant

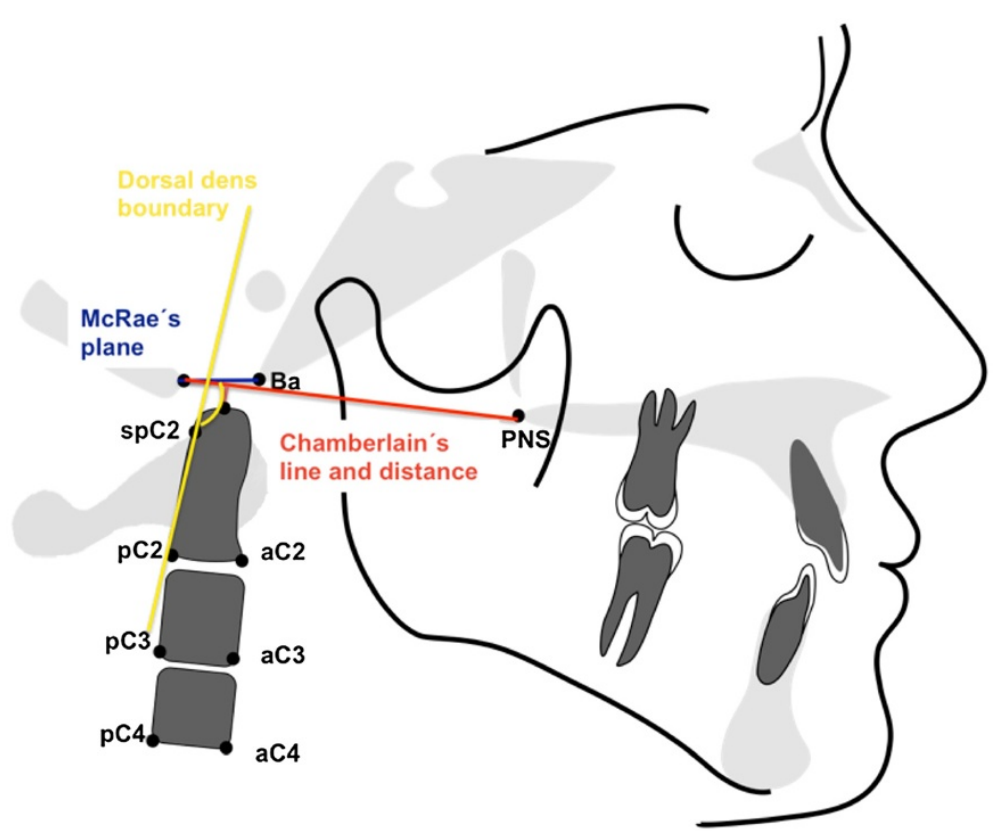

Figure 3 Angular and linear parameters of basilar impression. 


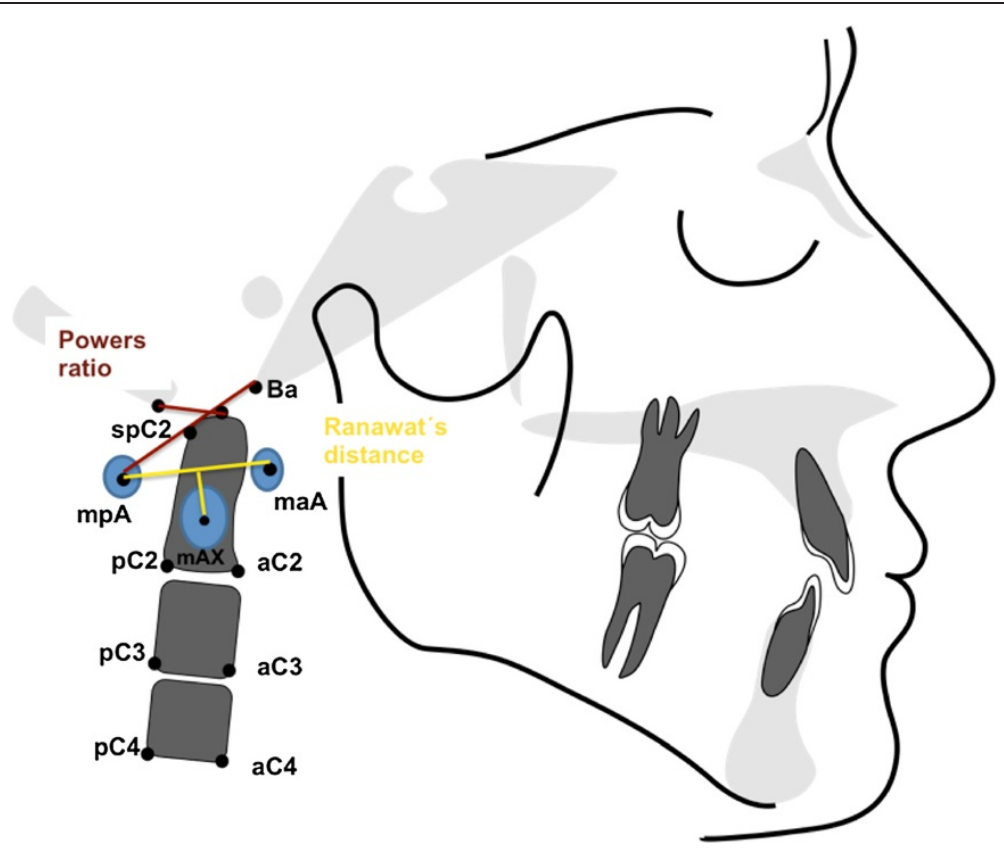

Figure 4 Angular and linear parameters of occipitoatlantal dislocation 1.

difference between both groups with regard to skeletal age, baseline skeletal findings, duration of treatment, or effect of treatment. Hence both groups were comparable (see Table 1). All cephalograms of the same patients were analyzed twice by the same investigator and checked for efficiency.

\section{Systematic error}

Dahlberg's combined systematic error [13] was calculated using the formula MF $=\sqrt{ }\left(\sum \mathrm{d}^{2} / 2 \mathrm{n}\right)$, where " $\mathrm{d}$ " is the difference between two measurements and " $n$ " the number of measurements performed in duplicate. Twenty cephalograms were arbitrarily selected and reanalyzed 3 months after first analysis. The mean values thus obtained were $0.6^{\circ}$ and $0.41 \mathrm{~mm}$.

\section{Results}

Mean values and standard deviations were calculated for the various (angular and linear) orthopedic values derived from the cephalograms in both appliance-specific patient

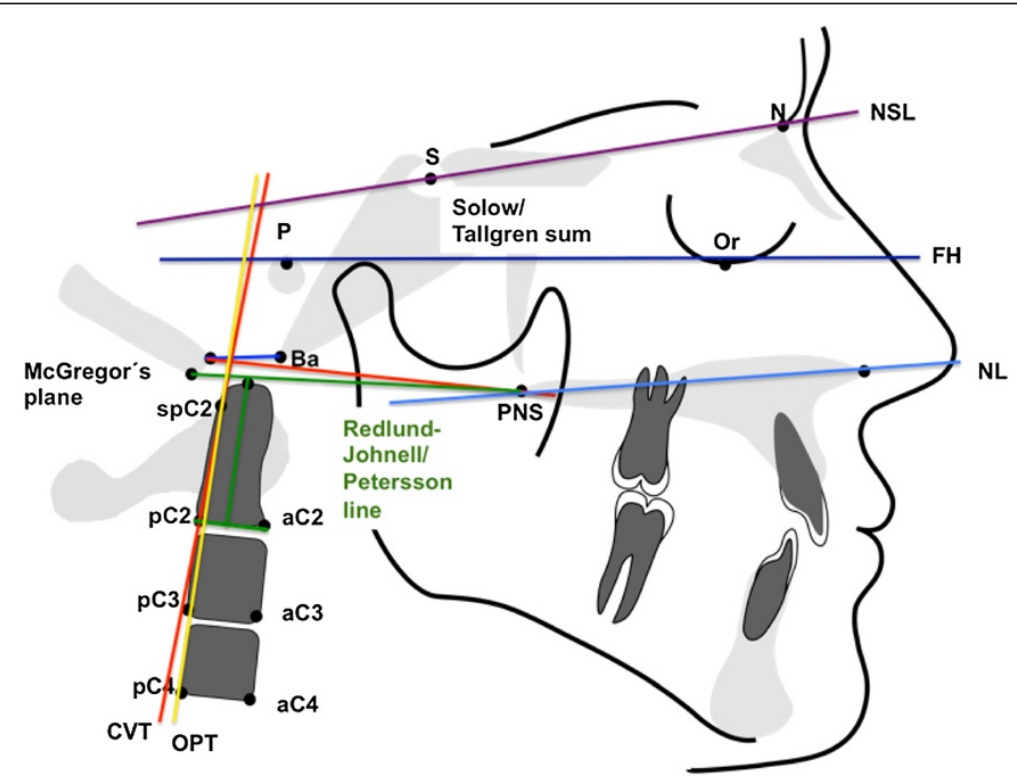

Figure 5 Angular and linear parameters of occipitoatlantal dislocation 2. 


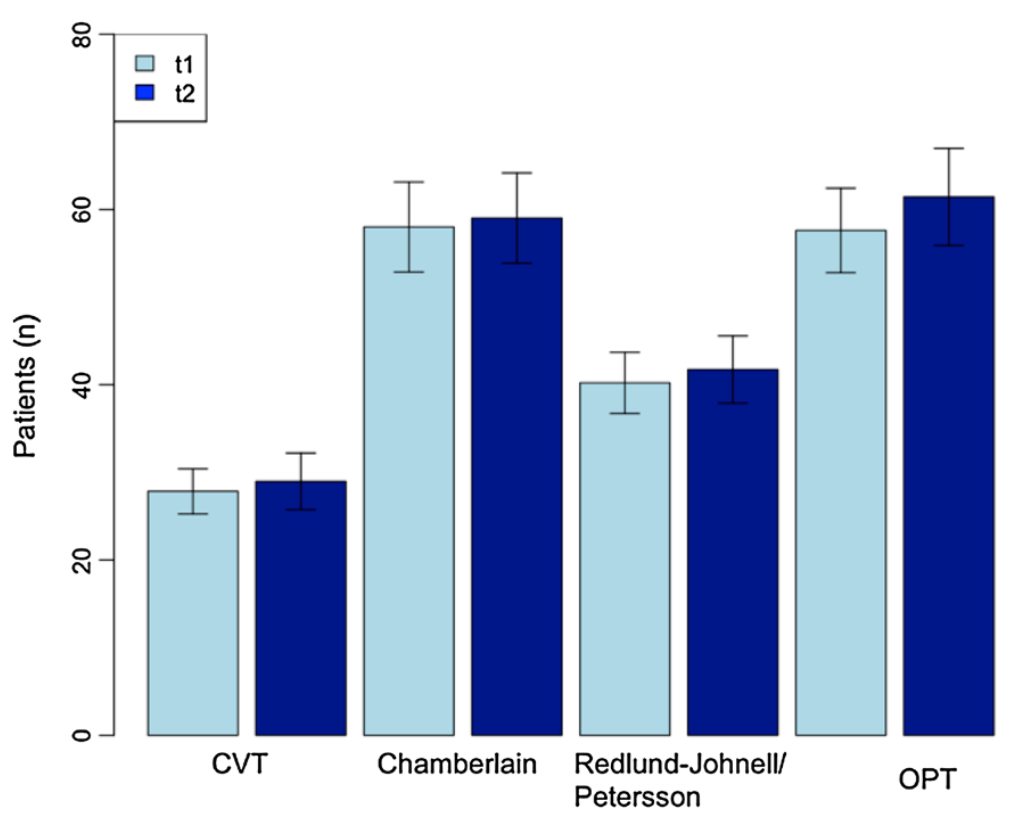

Figure 6 Bar chart of significant $\left({ }^{*}\right)$ and highly significant $\left(^{* *}\right)$ differences between atlantoaxial linear measurements before (t1) and after (t2) skeletal treatment.

groups. Figure 6 illustrates significant changes obtained for a number of atlantoaxial linear parameters based on the total sample of patients, including significant changes for Chamberlain by $0.93 \mathrm{~mm} \pm 2.58 \mathrm{~mm}(\mathrm{p}=0.0055)$ and highly significant changes for CVT $(\mathrm{p}=0.0003)$, OPT $(\mathrm{p}<0.0001)$ and Redlund-Johnell/Petersson $(\mathrm{p}<0.0001)$. Atlantoaxial distances increased in both treatment approaches. Based on the total sample of patients, the atlantoaxial angles revealed no major changes, while occipitoatlantal dislocation and basilar impression were falling short of statistical significance (Table 3).

Taken the different appliances into account, significant changes of atlantoaxial linear parameters were seen within the activator group (Table 4). The activator group revealed significant changes for Chamberlain $(p=0.0034)$ and McGregor $(p=0.0283)$ and highly significant changes for CVT $(\mathrm{p}=0.0006)$, OPT $(\mathrm{p}<0.0001)$ and Redlund-Johnell/ Petersson $(\mathrm{p}<0.0001)$. In the BJA group, only Powers ratio as the only linear parameter underwent significant changes; it decreased by $3.18 \pm 6.1 \mathrm{~mm}(\mathrm{p}=0.0477)$. In the activator group, no significant changes were seen in any of the atlantoaxial angular parameters. Significant changes in the BJA group were only seen for the NL-FH angle $(p=0.0064)$, thus being confined to one isolated parameter that was evaluated as part of the Solow/Tallgren sum of angles (Table 5).

\section{Discussion}

The present study demonstrates that cervical spine posture changes during treatment with functional orthodontic appliances. This is in accordance with Sonnesen et al. [15], who found craniocervical angles to be enlarged in the presence of dysgnathia and hyperlordosis and to be reduced by orthodontic treatment.

Interactions between the masticatory system and the cervical spine have been increasingly discussed over the years. Back in 1926, Schwarz [16] observed an association between head posture and jaw position. Head posture has been discussed to influence the mode of breathing during sleep and to have effects on craniofacial growth. Gresham

Table 3 Atlantoaxial angular measurements (summary)

\begin{tabular}{lcc}
\hline Angular parameters $\left(^{\circ}\right)$ & All patients & p-values \\
\hline Solow/Tallgren sum (modified) & & \\
$\quad$ OPT-FH & $0.75 \pm 7.85$ & 0.4535 \\
CVT-FH & $-0.67 \pm 7.99$ & 0.5102 \\
NL-FH & $-0.12 \pm 2.91$ & 0.7433 \\
$\quad$ NSL-FH & $0.43 \pm 2.73$ & 0.2136 \\
Clivus-dens angle & $0.23 \pm 7.92$ & 0.8207 \\
McGregor-CVT & $0.11 \pm 7.56$ & 0.9075 \\
McGregor-CVT & $-6.67 \pm 43.34$ & 0.2267 \\
McGregor-AT & $0.33 \pm 5.92$ & 0.7227 \\
AT-CVT & $-0.41 \pm 5.45$ & 0.6328 \\
(Ba-C)-McRae & $0.67 \pm 61.96$ & 0.9324 \\
(Ba-C)-AT & $0.51 \pm 4.59$ & 0.4747 \\
McRae-AT & $16.05 \pm 74.93$ & 0.1726 \\
Craniocervical angle (NSL-OPT) & $-0.53 \pm 8.18$ & 0.6054 \\
Atlas inclination (AT-FH) & $-0.09 \pm 4.27$ & 0.8987 \\
\hline
\end{tabular}

Data are given as mean differences $( \pm$ SD) between posttreatment and baseline values. 
Table 4 Atlantoaxial linear measurements (appliance-specific evaluation)

\begin{tabular}{|c|c|c|c|c|}
\hline Linear parameter $(\mathrm{mm})$ & Active group & p-values & BJA group & p-values \\
\hline McRae (Ba-opisthion) & $0.25 \pm 1.46$ & 0.3291 & $0.38 \pm 2.37$ & 0.4199 \\
\hline Chamberlain (opisthion-PNS) & $1.28 \pm 2.33$ & $0.0034^{*}$ & $0.69 \pm 2.95$ & 0.2394 \\
\hline McGregor (PNS-SO) & $1.12 \pm 2.80$ & $0.0283^{*}$ & $-0.29 \pm 4.00$ & 0.7127 \\
\hline $\mathrm{CVT}$ & $1.78 \pm 2.66$ & $0.0006^{* *}$ & $0.33 \pm 2.05$ & 0.4174 \\
\hline OPT & $4.74 \pm 3.73$ & $<0.0001^{* *}$ & $2.69 \pm 4.01$ & $0.0021^{*}$ \\
\hline AT & $-0.02 \pm 1.92$ & 0.9589 & $-0.67 \pm 2.72$ & 0.3543 \\
\hline Ranawat (mpA-maA-maX) & $0.35 \pm 1.39$ & 0.2005 & $-0.08 \pm 1.11$ & 0.7639 \\
\hline Powers ratio (SO-D/Ba-apA) & $1.74 \pm 6.31$ & 0.1564 & $-3.18 \pm 6.11$ & $0.0477^{*}$ \\
\hline Chamberlain's distance & $-0.13 \pm 2.35$ & 0.7466 & $-0.21 \pm 2.15$ & 0.6200 \\
\hline Redlund-Johnell/Petersson (McGregor-mC2) & $2.07 \pm 2.29$ & $<0.0001^{* *}$ & $0.85 \pm 2.40$ & 0.0835 \\
\hline
\end{tabular}

Data are given as mean differences $( \pm$ SD) between posttreatment and baseline values.

$\mathrm{p}$-values refer to intragroup comparisons.

Asterisks $\left({ }^{*}\right.$ or $\left.{ }^{* *}\right)$ indicate significant $(p<0.05)$ or highly significant $(p<0.001)$ differences.

and Smithells [9] furnished radiographic evidence that children habitually lacking an upright head posture reveal an Angle class II, a long-face syndrome, and enhanced lordosis of the cervical spine. This latter observation was confirmed by Balters [17]. Radiographic findings by Treuenfels and Torklus [18] suggested interactions between atlas position, dysgnathia and head posture. Hirschfelder and Hirschfelder [2] on the other hand did not confirm an Angle class characteristic atlas position. Mertensmeier and Diedrich [19] observed hyperlordosis of the cervical spine in over $40 \%$ of patients with class I or class II anomalies. Fink et al. [8] also demonstrated that occlusal changes have functional implications both within the craniocervical system and in the body area comprising the lumbar, pelvic and hip structures.

The cervical spine changes observed in the present study must be discussed as causally related to orthodontic treatment and/or produced by growth. In general, the straightening of the cervical spine is orthopedically desirable and consistent with physiological straightening during growth observed in Angle class II patients. In agreement with other studies prior orthodontic correction, the children revealed occipitoatlantal dislocation, basilar impression, hyperlordosis of the cervical spine, and retroflexion of the head $[3,20,21]$. A persistence of those findings led to atlas displacement, descendence of

Table 5 Atlantoaxial angular measurements (appliance-specific evaluation)

\begin{tabular}{|c|c|c|c|c|}
\hline Angular parameter & Active group & $p$-values & BJA group & $\mathrm{p}$-values \\
\hline \multicolumn{5}{|l|}{ Solow/Tallgren sum (modified) } \\
\hline OPT-FH & $0.98 \pm 8.15$ & 0.4867 & $0.20 \pm 7.76$ & 0.8945 \\
\hline CVT-FH & $0.17 \pm 9.58$ & 0.9181 & $-2.14 \pm 5.62$ & 0.0634 \\
\hline $\mathrm{NL}-\mathrm{FH}$ & $-0.16 \pm 1.71$ & 0.6000 & $-0.00 \pm 4.13$ & $0.0064^{*}$ \\
\hline NSL-FH & $0.24 \pm 2.13$ & 0.5174 & $0.6 \pm 3.51$ & 0.3917 \\
\hline Clivus-dens angle & $0.00 \pm 9.55$ & 0.9986 & $0.89 \pm 5.55$ & 0.4222 \\
\hline McGregor-CVT & $0.17 \pm 7.68$ & 0.8998 & $-0.01 \pm 7.49$ & 0.9938 \\
\hline McGregor-CVT & $-1.58 \pm 5.65$ & 0.1193 & $-14.90 \pm 66.98$ & 0.2623 \\
\hline McGregor-AT & $0.14 \pm 5.82$ & 0.9052 & $0.47 \pm 6.57$ & 0.7845 \\
\hline AT-CVT & $-0.65 \pm 5.37$ & 0.5562 & $-0.45 \pm 5.98$ & 0.7733 \\
\hline (Ba-C)-McRae & $9.93 \pm 60.47$ & 0.3525 & $-11.95 \pm 67.48$ & 0.3753 \\
\hline (Ba-C)-AT & $0.69 \pm 5.35$ & 0.5259 & $-0.02 \pm 3.46$ & 0.9825 \\
\hline McRae-AT & $12.42 \pm 70.11$ & 0.3847 & $23.05 \pm 89.05$ & 0.3332 \\
\hline Craniocervical angle (NSL-OPT) & $0.35 \pm 9.29$ & 0.8308 & $-2.13 \pm 6.71$ & 0.1174 \\
\hline Atlas inclination (AT-FH) & $-0.84 \pm 4.66$ & 0.3875 & $1.2 \pm 3.68$ & 0.2267 \\
\hline
\end{tabular}

Data are given as mean differences $( \pm$ SD) between posttreatment and baseline values. 
the hyoid, reducement of the pharyngeal size, persistence of mouth breathing, and further retrusion of the mandible [22]. Therefore, the straightening is an important therapeutic aspect.

These considerations raise the question to what extend orthodontic appliances are capable of straightening the cervical spine. Based on the total sample of patients, we were able to document a significant change of orthopedic parameters. Significant changes were more pronounced in the activator group. Our explanation for this finding is offered by the "Norwegian" activator system introduced by Andresen in 1935. The therapeutic effect of the activator is explained by the stimulation of masticatory muscles, lips and tongue, thereby transmitting functional stimuli to surrounding hard structures such as tooth, bone, and cervical spine $[23,24]$.

It appears that the mandibular advancement had an impact on the straightening of the cervical spine. From an orthopedic view, such straightening is consistent with physiological growth and therefore would seem to be desirable. As part of the observed changes were due to physiological growth, their causation can be attributed to a combination of orthodontic treatment and ongoing growth independent of the conducted treatment.

From the methodic point of view the used linear orthopedic parameters (Chamberlain, OPT, CVT, RedlundJohnell/Petersson) must be critically discussed: Values obtained for Chamberlain's distance are potentially distorted by difficulties in marking the posterior edge of the foramen magnum and the double contours of the hard palate [25]. McGregor's plane, which we used for Redlund-Johnell/Petersson analysis, offers the most reliable information of the linear parameters used $[20,26]$. In addition to yielding well-reproducible markings, the McGregor's plane represents a stable reference plane not undergoing any growth-related changes [27]. Values within the normal range and without significant changes were obtained for Ranawat's line, suggesting that this parameter also remains stable during physiological growth. All orthopedic reference values used in this study are gender-specific and based on adults only [28,29]. Since the patients in this study still grow, the cephalometric findings are bound to reflect combined effects of growth as well as treatment. In order to identify the net effect of treatment, a control group is needed in order to assess the growth effects involved. Since a historical control group with all relevant data has not been available in literature, the effects reported in this communication should be strictly regarded as gross effects.

\section{Conclusions}

Numerous studies have demonstrated correlations between orthopedic and orthodontic findings, also with regard to specific anomalies being associated with characteristic spinal postures. The null hypothesis of our study was sustained. Quantitative evidence was furnished that the dens moved closer to the spheno-occipital complex and that the dens axis and atlas were verticalized during skeletal advancement of the mandible thus compensating for the characteristic finding of cervical spine hyperlordosis in class II patients. There was a tendency for these effects to be more pronounced in the activator group than in the BJA group. Our finding of cervical spine changes during orthodontic treatment highlights the usefulness of interdisciplinary collaboration especially in patients with orthopaedic abnormalities.

\section{Competing interests}

The authors declare that they have no competing interests.

\section{Authors' contributions}

HKS carried out the study design, initiated the study and draft the manuscript. JW carried out the cephalometric analysis and participated in the data collection GK participated in the idea for this study, data collection, treated the patients. MO participated in the design of the study, performed the coordination of the study, helped to perform the cephalometric analysis and to draft the manuscript. All authors read and approved the final manuscript.

\section{Author details}

${ }^{1}$ Private praxis, Bahnhofstr, 55/1, Leonberg 71229, Germany. ${ }^{2}$ Department of Orthodontics, University Hospital Saarland, Kirrberger Str. 100, Homburg/Saar 66424, Germany. ${ }^{3}$ Department of Orthodontics, University Hospital Giessen and Marburg, Georg-Voigt-Strasse 3, Marburg 35039, Germany.

Received: 31 January 2014 Accepted: 21 February 2014

Published: 24 March 2014

\section{References}

1. Dußler E, Raab P, Kunz B, Kirchner S, Witt E: Mandibuläre Mittellinienverschiebungen und Asymmetrien des Halte- und Bewegungsapparates bei Kindern und Jugendlichen. Man Med 2002, 40:116-119.

2. Hirschfelder U, Hirschfelder H: Sagittale Kieferrelation und Wirbelsäulenhaltung: Untersuchungen zur Frage einer Abhängigkeit. Fortschr Kieferorthop 1987, 48:436-448.

3. Huggare J, Houghton P: Associations between atlantoaxial and craniomandibular anatomy. Growth Dev Aging 1996, 60:21-30.

4. Korbmacher H, Eggers-Stroeder G, Koch L, Kahl-Nieke B: Correlation between anomalies of the dentition and pathologies of the locomotor system - a literature review. J Orofac Orthop 2004, 65:190-230.

5. Lippold C, van den BL, Hohoff A, Danesh G, Ehmer U: Interdisciplinary study of orthopedic and orthodontic findings in pre-school infants. J Orofac Orthop 2003, 64:330-340.

6. Duyzings JAC: Kieferorthopädie und Körperhaltung. Dtsch Zahnärzt/ 1955 10:19-21.

7. Prager A: Vergleichende Untersuchungen über die Häufigkeit Zahnstellungs- und Kieferanomalien bei Patienten mit Deformitäten der Wirbelsäule. Fortschr Kieferorthop 1980, 41:163-168.

8. Fink M, Tschernitschek H, Stiesch-Scholz M, Wähling K: Kraniomandibuläres System und Wirbelsäule-Funktionelle Zusammenhänge mit der Zervikal und Lenden-Becken-Hüft-Region. Man Med 2003, 41:476-480.

9. Gresham H, Smithells PA: Cervical and mandibular posture. Dent Rec 1954, 74:261-264.

10. Biedermann H, Koch L: Zur Differentialdiagnose des KISS-Syndroms. Man Med 1996, 34:73-81.

11. Korbmacher H, Koch L, Eggers-Stroeder G, Kahl-Nieke B: Association between orthopaedic disturbances and unilateral crossbite in children with assymmetry oft the upper cervical spine. Eur J Orthod 2007, 29:100-104.

12. Festa F, Dattilio M, Vecchiet F: Effects of horizontal oscillation of the mandible on the spinal column of the rat in vivo using radiogrphic monitoring. Orthognatodonzia Ital 1997, 6:539-550. 
13. Dahlberg G: Statistical methods for medical and biological students. New York: Interscience Publications; 1940.

14. Lippold C, Danesh G, Hoppe G, Drerup B, Hackenberg L: Sagittal spinal posture in relation to Craniofacial Morphology. Angle Orthod 2006 76:625-631.

15. Sonnesen $\mathrm{L}$, Bakke $\mathrm{M}$, Solow B: Temporomandibular disorders in relation to craniofacial dimensions, head posture and bite force in children selected for orthodontic treatment. Eur J Orthod 2001, 23:179-192.

16. Schwarz AM: Kopfhaltung und Kiefer. Z Stomatol 1926, 24:669-744.

17. Balters W: Die Wirbelsäule aus der Sicht des Zahnarztes. Zahnarztl Mitt 1964, 9:408-412

18. Von Treuenfels H, Torklus D: Die Relation von Atlasposition, prognather und progener Kieferanomalie. Z Orthop 1983, 121:657-664.

19. Mertensmeier I, Diedrich P: Der Zusammenhang von Halswirbelsäulenstellung und Gebissanomalien. Fortschr Kieferorthop 1992, 53:26-32.

20. McGregor M: The significance of certain measurements of the skull in the diagnosis of basilar impression. Br J Radiol 1948, 21:171.

21. Soni P, Sharma V, Sengupta J: Cervical vertebrae anomalies - incidental findings on lateral cephalograms. Angle Orthod 2008, 78:176-180.

22. Broich I: Aspekte der Bewegungsentwicklung und des Bewegungsverhaltens in der Kieferorthopädie. Krankengymnastik (KG) 1996, 48:10.

23. Fränkel C, Fränkel R: Der Funktionsregler in der orofazialen Orthopädie. Heidelberg: Hüthig Buch Verlag; 1992.

24. Sander F, Wichelhaus A: Skelettale und dentale Veränderungen bei der Anwendung der Vorschubdoppelplatte. Fortschr Kieferorthop 1995, 56:127-139.

25. Tassanawipas A, Mokkhavesa S, Chatchavong S, Worawittayawong P: Magnetic resonance imaging study of the craniocervical junction. J Orthop Surg 2005, 13:228-231.

26. Johnell-Redlund I, Petersson H: Radiographic measurements of the craniovertebral region. Designed for evaluation of abnormalities in rheumatoid arthritis. Acta Radiol Diagn 1984, 25:23-28.

27. Gutmann G: Beitrag zur quantitativen und qualitativen Analyse des Röntgenbildes der Halswirbelsäule im seitlichen Strahlengang. Man Med 1979, 3:49-56.

28. Ranawat CS, O'Leary P: Cervical spine fusion in rheumatoid arthritis. J Bone Joint Surg 1979, 61:1003-1010.

29. Wolf U, Lassen J, Traub F, Wilke A: Mobilität der Kopfgelenke bei chronischer Polyarthritis- Korrelation klinisch-manueller Untersuchungsbefunde mit bildgebenden Verfahren - Teil 1: Material und Methoden. Man Med 2000, 38:270-273.

doi:10.1186/1746-160X-10-7

Cite this article as: Ohnmeiß et al.: Therapeutic effects of functional orthodontic appliances on cervical spine posture: a retrospective cephalometric study. Head \& Face Medicine 2014 10:7.

\section{Submit your next manuscript to BioMed Central and take full advantage of:}

- Convenient online submission

- Thorough peer review

- No space constraints or color figure charges

- Immediate publication on acceptance

- Inclusion in PubMed, CAS, Scopus and Google Scholar

- Research which is freely available for redistribution 